\title{
UCLA
}

Mester

Title

Estuvo aquí

Permalink

https://escholarship.org/uc/item/61b2b7b0

Journal

Mester, 15(1)

Author

Galeano, Juan Carlos

Publication Date

1986

DOI

10.5070/M3151013753

Copyright Information

Copyright 1986 by the author(s). All rights reserved unless otherwise indicated. Contact the author(s) for any necessary permissions. Learn more at https://escholarship.org/terms

Peer reviewed 


\section{ESTUVO AQUÍ}

\section{Siempre}

En el golpe del agua

En la proa despedazada del sueño

En alguna voz

Permanece ella

Mañana me iré de este lugar

Juan Carlos Galeano

University of Kentucky-Lexington 